\title{
Retrospecting Polish Audio Engineering Society Membership on 20th Anniversary of the Polish Section of the Audio Engineering Society
}

\author{
Bożena KOSTEK, Marianna SANKIEWICZ \\ Audio Engineering Society Fellows \\ Gdansk University of Technology \\ Multimedia Systems Department \\ Narutowicza 11/12, 80-233 Gdańsk, Poland \\ e-mail: bozenka@sound.eti.pg.gda.pl \\ mar@use.pl \\ (received April 16, 2011)
}

\begin{abstract}
In this article some key events concerning founding Polish Section of the Audio Engineering Society were presented. In addition, the history covering International Symposia on Sound Engineering and Mastering was outlined. Also, papers contained in this issue were shortly reviewed.
\end{abstract}

Keywords: audio and sound engineering, musical acoustics.

\section{Introduction}

The initiative of organizing the Polish Section of the Audio Engineering Society was undertaken twenty years ago by scientists of the Sound Engineering Department at the then Faculty of Electronics, of Gdansk Technical University (TUG). It was first such an initiative in the countries of Central and Eastern Europe, which in 1989 regained freedom to decide on their own fate. Herein Gdańsk, in 1991, Tim Shelton, then President of the AES, officially inaugurated the functioning of the Polish Section, already active from 1990.

It should be recalled, however, that the Audio Engineering Society, founded in the United States in 1948, has grown to become an international organization that unites audio engineers, scientists, and other individuals with an interest or involvement in the professional audio industry. The membership largely comprises not only of engineers developing audio devices or products and persons working in audio content production, but also includes acousticians, audiologists, academics, and other disciplines related to audio. The AES is the only world-wide profes- 
sional society devoted exclusively to audio technology. It operates through local AES section events and professional networking. The AES organizes Conventions, held annually both in the US and Europe, which include scientific presentations, student activities, workshops, and exhibitions. Additional conferences and regional summits are held periodically throughout Latin America, Asia, Europe, and North America. The AES publishes a peer-reviewed journal, the Journal of the Audio Engineering Society (JAES).

What has been done for those twenty years by Polish acousticians acting under the AES banner, which enables them to recall memories of this period with pleasure and satisfaction?

A concept to create a direct link between Polish audio engineers and the World community of audio engineers, grouped within the Audio Engineering Society, was born in late sixties in the harbor city of Gdansk, at the Faculty of Electronics. In 1982 Gustaw Budzyński became the Head of the Department, and at the same time the Department changed its name to the Department of Sound Engineering. He introduced, established and then consequently developed a new learning program of the first, and for a long time the only, specialty known in Poland as Sound Engineering. The specialization comprised deliberately chosen elements of various disciplines: physiology and psychology of perception, oscillation theory, theory of sound, architectural acoustics, musical acoustics, electroacoustics, sound recording and reproduction, studio techniques, etc. Such professional arrangement, then unique in Poland, quickly became very popular among students, which, consequently, graduated as M.Sc. in Sound Engineering. Soon, they gained a renown mark as sound engineers in numerous radio and television stations, in film production enterprises, music theatres, all over the country. Together with their teachers and professional colleagues, they formed an informal circle, bound together by their mutual professional contacts and their scientific interests.

A need, however, of a more recognized and broader contacts, including those on an international scale, became obvious. The Audio Engineering Society, with its international character and professional proximity to Gdansk circle of sound engineers, seemed to be the most natural and promising possibility to realize the need. First contacts were established in 1986 and 1987 due to the presentations of papers read during the 80th and 82nd Conventions by the assistants K. Muzalewski and A. Czyżewski (a leading person among Polish scientists in this domain, now). Then, an advantage was taken of the nearest opportunity created by the 86th AES Convention organized in Hamburg.

Then, it was decided to enter into formal cooperation with the AES. A paper by G. Budzyński, M. Sankiewicz (1989) entitled: "The definition of sound-image quality and its influence on sound engineering concepts" was accepted to be presented at the appropriate session of the 86th AES Convention in Hamburg. The session was chaired by Stanley P. Lipschitz, who very kindly supported this presentation, and moreover, efficiently helped to determine Polish membership in the AES. The next initiative toward founding the Polish Section was a London 
meeting with Tim Shelton, the AES President, Roger Furness, the AES Director and two representatives from Gdansk, Andrzej Czyżewski and Bożena Kostek, during which all guidelines for establishing and maintaining a Section, the AES bylaws, and the membership were discussed. At this time, Tim Shelton accepted the invitation to visit Gdańsk and took part in founding the Polish Section of the AES (Fig. 1).

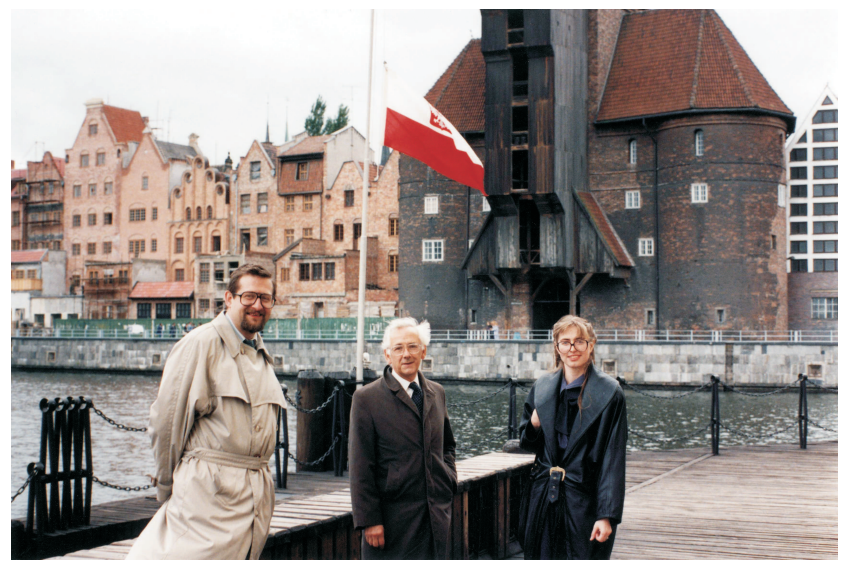

Fig. 1. Tim Shelton (in the middle), Bożena Kostek and Andrzej Czyżewski in the Old City of Gdansk (1991).

Organizing the Polish AES Section became real during the session of the National Sound Engineering Symposium held at the Gdansk Technical University in 1991. Then, the AES President Tim Shelton came to Gdansk Symposium and inaugurated the activities of the newly founded PS-AES. During this session Prof. M. Sankiewicz was elected first Chair of the Polish Section. A steady development of the Section followed. The next PS Section Chairs were: Andrzej Dobrucki, Jan Adamczyk and Zbigniew Kulka. Polish members of the PS, including students, participated yearly in the AES Conventions. The number of contributed papers depicts their activity. It is also very important to mention that four members of the PS AES have received prestigious Fellowship of the Society, they are: Andrzej Czyżewski (2000), Marianna Sankiewicz (2005, and Citation in 1998) (Fig. 2), Andrzej Dobrucki (2007), Bożena Kostek (2010). In 2011 Andrzej Brzoska was nominated for Fellowship. Also Jan Adamczyk was recognized by the AES, and got the Board of Governors Award (2005). It should also be mentioned that two other AES members of Polish origin, were the recipients of these prestigious awards, namely Stefan Kudelski got his Honorary Membership in 1977 and, later in 1984, the Gold Medal, and Wieslaw Woszczyk, former President of the AES received his Fellowship in 1996. During these past years some members were honored with the AES life-members, i.e.: Jan Adamczyk, Gustaw Budzyński, Bogdan Janta-Połczyński, Janusz Renowski, Marianna Sankiewicz (life-fellow), Krzysztof Wojtowicz. 


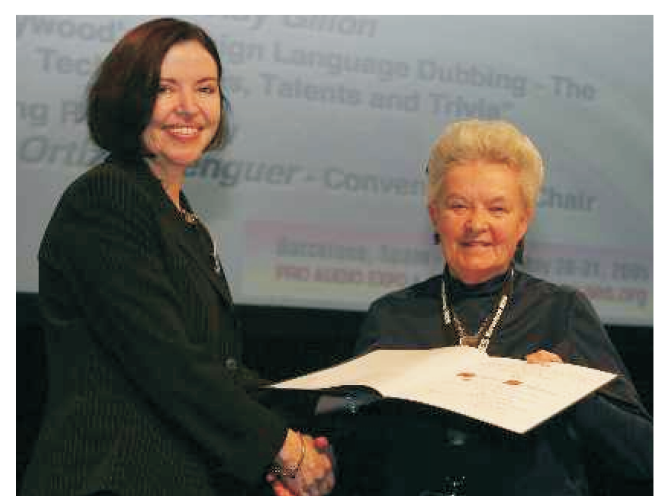

Fig. 2. Marianna Sankiewicz receiving the AES Fellowship Award from Theresa Leonard, AES President, during the 118th AES Convention in Barcelona.

It should also be pointed out that Polish Section organized students' laboratories organized at the annual European Conventions of the AES (Fig. 3). The Conventions helped immensely in the scientific and professional development of participating students. Polish students took part in the AES student Competitions. They were the recipients of the Student Design Competition awards, as well as the Recording Competition. Students from Wroclaw University of Technology, Gdansk University of Technology and Fryderyk Chopin Music University of Warsaw received several prizes in these world-wide student competitions.

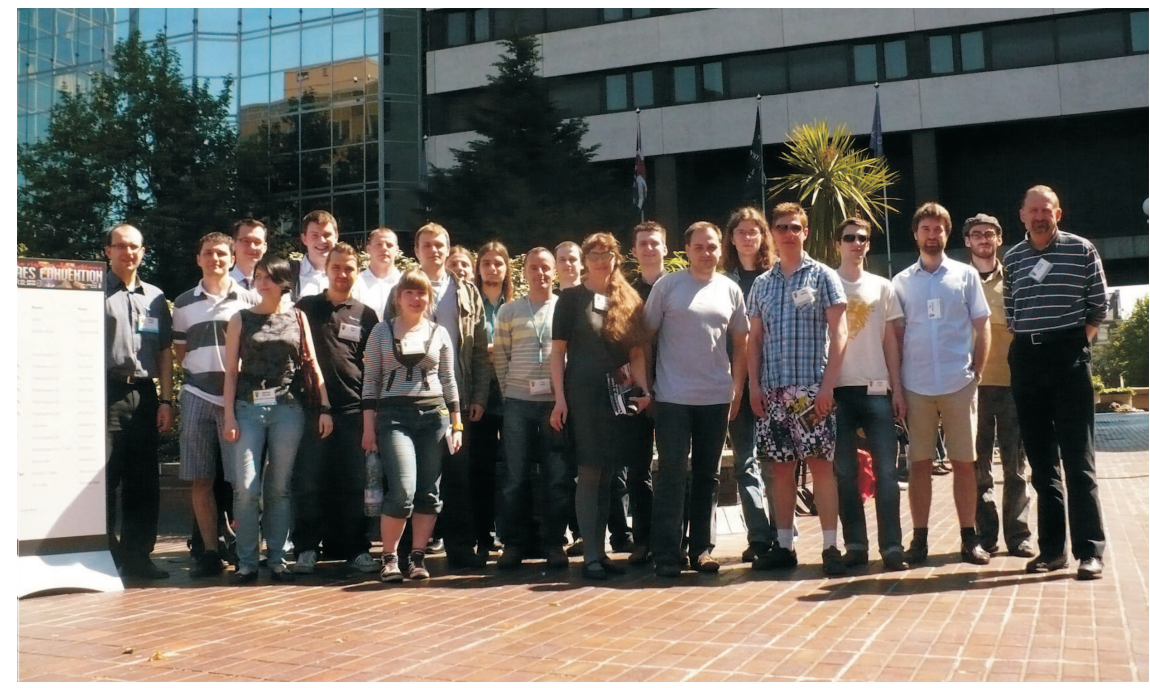

Fig. 3. Students and staff from the Multimedia Systems Department participating in the 128th AES Convention in London in 2010.

In 1995 M. Sankiewicz was proposed a candidate to the newly established function of AES Vice-President for Central Europe, and then elected for a two- 
year term. Acting as AES officer she initiated a rapid enlargement of the Central Europe Region towards the East, by founding several new AES Sections in Lithuania, Ukraine, Russia, Belarus, and a new Student Section in Poland, as well as corroborating activities of the formerly existing Sections of this Region.

The influence of the cooperation with the AES authorities was beneficial to the development of Polish teams of sound engineers and acousticians. The PSAES was accepted as a professional and scientific national organization and jointly within the Polish Acoustical Society represented this branch within the Polish Academy of Sciences.

The next Polish new AES officer in the AES governing bodies was Bożena Kostek. In 2003 she was elected Vice-President of the Audio Engineering Society for Central Europe, and in 2005 she was once again appointed AES Vice President for Central Europe Region. From 2007 to 2009 she served as the AES Governor. In 2009, she was once again nominated for Vice-President of the Audio Engineering Society, and elected for this position. In 2011 she was nominated as a candidate for the AES Governor. Both Vice-President and Governor are members of the Board of Governors, which is the controlling and directing body of the Society. It should also be mentioned that Magdalena Plewa, a student of the Cracow AGH University of Science and Technology was elected Vice Chair of the Student Assembly Delegate of the AES.

Polish AES Section Symposia have been organized biannually since 1985, i.e. they began six years before the Polish Section had officially started its activity during the 4th Symposium held in Gdansk in 1991. They were held under the auspices of the Polish Section of the Audio Engineering Society and the Polish Academy of Sciences and provided a valuable forum for the knowledge exchange based on diverse experiences and a wide range of technical and music expertise. Since that time, at every Symposium a new team of Section Officers and Section Committee Members has been elected. Every Symposium was unique in its way, but it is important to recall some of them. The 6th Symposium on Tonmeistering and Sound Engineering was organized in cooperation with the F. Chopin Warsaw Music Academy, and in particular with its Tonmeistering Faculty, on the occasion of its 40th jubilee. The Symposium was sponsored by the Polish Radio Corporation, whose many employees being AES members, and also by the Ministry of Culture and Art.

The opening ceremony took place in the Academy concert hall. The Chairmen of the Organizing Committee welcomed all participants and particularly warmly the guests from abroad. Then the Rector of the Academy spoke on the occasion of the Faculty Jubilee. A pleasant event for the Polish AES Section was an announcement by the Director of the Polish Radio that Marianna Sankiewicz, one of the Polish AES Section founders and the present AES Vice-President for the Central European Region, was awarded a medal for her 50 years of cooperation with the Polish Radio, this being issued by the Polish Radio on its 70th anniversary. 
The Symposium was inaugurated by a lecture presented by Jürgen Meyer, from Berlin, who demonstrated to listeners how timbre qualities relate to different performers seating arrangement. The presentation included several selected excerpts from famous composers' works, typical of various music styles. The convincing presentation gained a standing ovation from the audience. The guests from abroad read ten papers, among them Dan Popescu from Copenhagen, the former AES Vice President, who spoke about Broadcasting in Denmark. Another active AES member, the AES Committee Chairman Wiesław Woszczyk presented his concepts on future "Home Theater System", and in an invited paper the President of the VDT (Vereinigung Deutscher Tonmeister) Günther Griewisch developed his ideas about the profession of Tonmeister in a United Europe. Among important guests was Gerhard Steinke who participated in the 5th Symposium on Sound Engineering and Mastering in Wroclaw in 1993, and Dr. Karl-Otto Baeder, Vice-President of the Audio Engineering Society for Central Europe visiting ISSEM'99 (September 1999), Prof. Kristian Kroschel (University of Karlsruhe), Prof. George Papanikolaou (University of Thessaloniki) and many others; see some photos from the Multimedia Systems photo gallery (Fig. 4; MSD photo gallery).

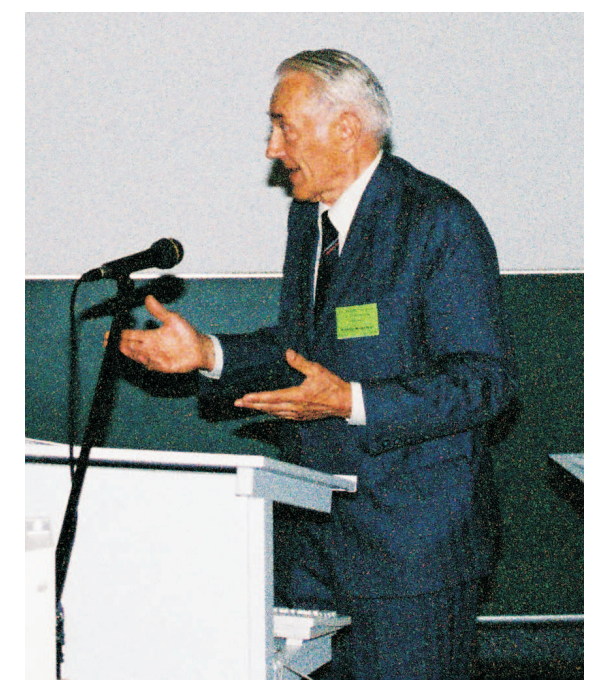

Fig. 4. Prof. Gustaw Budzyński presenting a paper at the ISSEM'99.

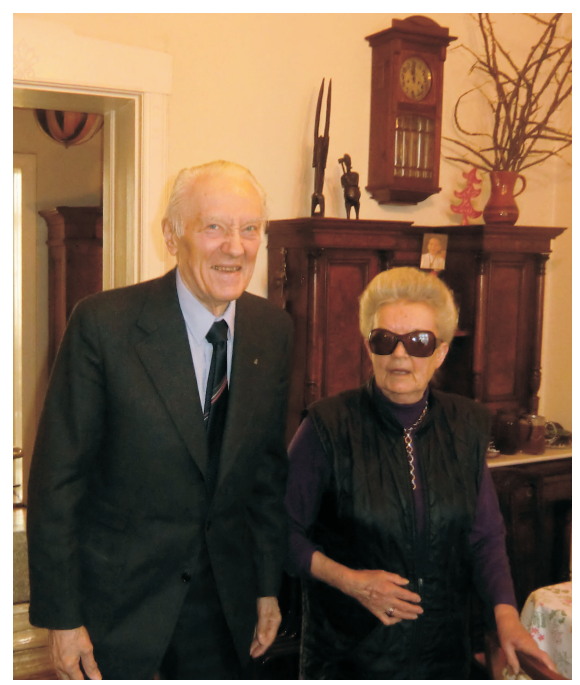

Fig. 5. Prof. Gustaw Budzyński and Marianna Sankiewicz.

At the end of May, 2000, Gdańsk acousticians hosted a very important visitor, namely, the President-Elect of the Audio Engineering Society, Professor Roy Pritts, of Colorado University, Denver, USA. Limited to three and a half days only, the time spent in Poland was devoted by R. Pritts entirely to meetings with Gdansk AES members, and especially with students. Although the time was insufficient to visit other active centers of the Polish AES Section, we had guests from other AES authorities. Also, the former VP AES Markus 
Erne visited Gdansk (2003). Prof. Wiesław Woszczyk, AES President participated in the International Symposium on Sound and Vision Engineering and Mastering hold in Gdansk in 2007 and he gave a plenary talk to the Symposium participants. Many other interesting papers were presented and evoked animated discussions. It is worth to mention that extended versions of papers presented during the 12th International Symposium on Sound and Vision Engineering and Mastering (ISSVEM'07) were critically reviewed and then published in Archives of Acoustics. Sound engineering is an interdisciplinary and rapidly expanding domain. It covers many aspects, including: sound perception (SzCZEPAŃSKAAntosik, 2008), studio and sound mastering technology (Hen et al., 2008; Mickiewicz, Jeleń, 2008; Pruchnicki, Plaskota, 2008), music information retrieval providing a part of multimedia applications (CHUDY, 2008; WiTULSki, ŁUKAsIK, 2008; WoŁKowicz et al., 2008; WóJCIK, Kostek, 2008; Żwan, 2008), electroacoustics (BoBiński, BielaWski, 2008; KORYCKI, 2008; KulKA, WoszCZEK, 2008; MALECZEK, 2008), sound synthesis (MŁYŃSKA, 2008), sound restoration (MAZIEWSKi, 2008; PAstuszak 2008), and others (MikOŁOWICZ, 2008). These topics have been covered by this issue of Archives of Acoustics. The present 14th Symposium is to take place in Wroclaw on May 19-21, 2011. The Honorary Chairs of the ISSET 2011 are Prof. M. Sankiewicz and Prof. G. Budzyński (Fig. 5). On behalf of the Organizers of the ISSET 2011 it was decided that a special issue of Archives of Acoustics devoted to sound engineering would be published. The emphasis will be put on extensive research related to sound engineering conducted in many academic centers. Many papers from scientists working in sound engineering and acoustics domains from Poland and abroad were gathered, peer-reviewed and published. There is a very rich scope of articles, that will be cited here.

The first is a paper by BUDZYŃSKI (2011) which provides a very thorough review on important, yet often disregarded, sound quality aspects related to acoustics associated with sacral buildings and liturgy ceremonies. The article focuses on a number of features that need to be considered in order to insure sound quality appropriate for sacral buildings. These features are further discussed in a very appealing manner based on the perspective of the Author's own research and experience, and on the comprehensive literature studies.

BEAUCHAMP (2011) provided a comprehensive study of correlating specific acoustic parameters with their perceptual timbre dimensions. The aim of this study was to build a synthesis system where a minimal set of independent but perceptually important parameters are used to control and synthesize sounds of traditional Western music culture instruments. The paper formulates and answers the questions by giving examples of results obtained in subjective tests in studies performed by the Author.

KLONARI et al. (2011) investigated whether recorded musical tones played at various pitches on selected members of the wind instruments are perceived as being equal in loudness when presented at the same $A$-weighted level to listen- 
ers. This psychophysical investigation showed instrument type- and pitch-related effects that could be connected to spectral properties of sounds investigated.

Absolute pitch (AP) is one of the most intriguing phenomena of the auditory memory. RAKOWSKI and RogOWSKI (2011) in their paper included a general discussion on the "absolute pitch" phenomenon, and presented various concepts concerning AP definition. They also included a presentation of the experiment concerning frequency range in which absolute pitch appears, and a discussion on the experimental results.

The paper by CARRAL et al. (2011) presents an analysis of timbre differences between single and double reed musical instruments and tries to prove that it is possible to make a modified single reed version of an oboe. The Authors constructed a reed mouthpiece and attached it to an oboe. A question concerning timbre of such a new instrument had been formulated, and then answered by subjective evaluation, and finding an objective measure.

There are also two papers related to Music Information Retrieval (MIR) with the focus on efficient music browsing. The paper by BISESI and PARNCUTT (2011) explores the relationship between accents and expression in piano performance. They proposed and tested two models for automatic rendering of expressive performance. GŁACZYŃSKI and ŁUKASIK (2011) discussed first approaches to automatic generation of music audio summary, and introduced a method for extracting a music thumbnail - a fragment of continuous music of a given duration time that is most similar to the entire music piece. The important part of this article is dedicated to generating music summary of pieces of popular music in audio domain. Another topic which is related to MIR is presented by MIKA and KLECZKOWSKI (2011). The Authors addressed the problem of signal separation in MIR applications such as for example automatic music transcription or musical instrument identification. They used Independent Component Analysis (ICA) for a single channel audio separation. In their approach, they proposed and tested different measures of distance of components after the process of decomposition. The perceptual quality of separation obtained with the measures of the proposed distance was evaluated by listening tests.

Kin and Plaskota (2011) presented a comparison of some sound attributes perceived at multichannel and stereo playback of musical recordings. They investigated the width of a virtual source, coherence impression, total size of sound scene, general quality as well as the balance after the format reduction compliant with ITU recommendation. The results show that the evaluation of these attributes depends on the way the original audiosphere have been created in a surround system. PleWA and KLECZKOWSKI (2011) proposed a decision supporting method, which bases on the mapping of the actual position of a sound source to its position in the reproduced acoustic scene. The aim of this system is to choose and configure a stereo microphone technique based on the so-called localization curves. Another subject related to studio technology was presented in the article by SiteK and Kostek (2011). The aim of this paper was to study 
the preference for surround microphone techniques used in the recording of choir and instrumental ensemble.

WOSZCZYK (2011) started his paper with a statement that: "The function of acoustic enclosure is to contain the sound produced by musical instruments and voices, and to distribute it adequately to the musicians and the audience". Then he introduced the active acoustics concept with examples from literature and the McGill's Virtual Acoustic Technology (VAT) which offers new solutions in the key areas of performance by focusing on the electroacoustic coupling between the existing room acoustics and the simulated acoustics.

The threat environmental noise poses to human health has become an issue of considerable significance. This problem was discussed by CzYŻEWski et al. (2011). A system for noise monitoring was designed and developed at the Multimedia Systems Department of the Gdansk University of Technology, Poland. Through the grid of monitoring stations, the solution produces noise maps, based on and verified on the basis of live data. The proposed noise prediction model, implemented on a cluster-type computer, allows for fast and accurate updates of generated maps.

Sound engineering practice means audio equipment as well. KULKA (2011) delivered a very thorough review on the state-of-the art of the development of digital microphones and loudspeakers, as well as on the advances in digital audio, particularly in a direct digital transduction, that makes it possible to create the all-digital audio recording and the reproduction chains potentially having several advantages over existing analog systems. The nonlinear distortions are an important degradation cause of the quality of transmitted audio signals. DoBRUCKI (2011) dealt with the problem of nonlinear distortions in electroacoustic devices and showed the main causes of nonlinearity. The implementation of a new original method of distortion measurement was also presented in this article.

SzCZERBA et al. (2011) reviewed first parametric audio coders and discussed novel technologies introduced in a low-complexity, low-power consumption audio decoder and a music synthesizer platform developed by the Authors. The decoder uses a parametric coding scheme based on the MPEG-4 Parametric Audio standard. In order to keep the complexity low, most of the processing is performed in the parametric domain. This parametric processing includes pitch and tempo shifting, volume adjustment, selection of psychoacoustically relevant components for synthesis and stereo image creation.

This issue has highly benefited from the authors' contributions as well as from several anonymous reviewers who carefully reviewed all papers.

\section{References}

1. Bisesi E., Parncutt R. (2011), An Accent-Based Approach to Automatic Rendering of Piano Performance: Preliminary Auditory Evaluation, Archives of Acoustics, 36, 2, 283-296. 
2. Bobiński P., Bielawski B. (2008), Midi controlled audio-DSP system, Archives of Acoustics, 33, 1, 79-86.

3. Budzyński G., Sankiewicz M. (1989), The definition of sound-image quality and its influence on sound engineering concepts, 86th Audio Eng. Soc. Convention, Paper No. 2747.

4. Budzyński G. (2011), Sacral Sound-Engineering, Archives of Acoustics, 36, 2, 199-224.

5. Beauchamp J.W. (2011), Perceptually correlated parameters of musical instrument tones, Archives of Acoustics, 36, 2, 225-238.

6. Carral S., Vergez C., Nederveen C.J. (2011), Toward a single reed mouthpiece for the oboe, Archives of Acoustics, 36, 2, 267-282.

7. Chudy M. (2008), Automatic identification of music performer using the linear prediction cepstral coefficients method, Archives of Acoustics, 33, 1, 27-33.

8. Czyżewski A., Kotus J., Szczodrak M. (2011), Creating Acoustic Maps Employing Supercomputing Cluster, Archives of Acoustics, 36, 2, 395-418.

9. Dobrucki A. (2011), Nonlinear distortions in electroacoustic devices, Archives of Acoustics, 36, 2, 437-460.

10. GŁaczyński J., Łukasik E. (2011), Automatic generation of music summary. A Thumbnail approach, Archives of Acoustics, 36, 2, 297-309.

11. Hen P., Kin M.J., Plaskota P. (2008), Conversion of stereo recording to 5.1 format using head-related transfer functions, Archives of Acoustics, 33, 1, 7-10.

12. Kin M.J., Plaskota P. (2011), Comparison of sound attributes of multichannel- and mixed-down stereo recordings, Archives of Acoustics, 36, 2, 333-345.

13. Klonari D., Pastiadis K., Papadelis G., Papanikolaou G. (2011), Effect of instrument type and pitch on loudness of musical sounds following A-weighted level equalization, Archives of Acoustics, 36, 2, 239-250.

14. KoRYCKI R. (2008), Implementation of dynamic range controller on digital signal processor, Archives of Acoustics, 33, 1, 87-91.

15. Kulka Z., Woszczek P. (2008), Implementation of digital sigma-delta modulators for high-resolution audio digital-to-analog converters based on field programmable gate array, Archives of Acoustics, 33, 1, 93-101.

16. Kulka Z. (2011), Advances in digitization of microphones and loudspeakers, Archives of Acoustics, 36, 2, 419-436.

17. MaleczeK S. (2008), Optimisation of the total harmonic distortions of the acoustic vacuum tube push-pull amplifier, Archives of Acoustics, 33, 1, 103-109.

18. Maziewski P. (2008), Modulation frequency constraints on wow and flutter determination, Archives of Acoustics, 33, 1, 125-131.

19. Mickiewicz W., Jelé́ J. (2008), Surround mixing in pro tools LE, Archives of Acoustics, 33, $1,11-17$.

20. MikA D., KleczKowski P. (2011), ICA-based single channel audio separation: new bases and measures of distance, Archives of Acoustics, 36, 2, 311-331. 
21. MikoŁowicz M. (2008), The electromagnetic microwave sensors in improving speech intelligibility after laryngectomy, Archives of Acoustics, 33, 1, 133-138.

22. MŁYŃSKA A. (2008), Output filter implementation for digital waveguide clarinet model, Archives of Acoustics, 33, 1, 111-116.

23. Pastuszak P. (2008), MTS pilot tone tracking for "wow" distortion determination, Archives of Acoustics, 33, 1, 117-123.

24. Plewa M., Kleczkowski P. (2011), Choosing and configuring a stereo microphone technique based on localisation curves, Archives of Acoustics, 36, 2, 347-363.

25. Pruchnicki P., Plaskota P. (2008), Automatic measuring system for head-related transfer function measurement, Archives of Acoustics, 33, 1, 19-25.

26. Rakowski A., Rogowski P. (2011), Absolute pitch and its frequency range, Archives of Acoustics, 36, 2, 251-266.

27. Sitek A., Kostek B. (2011), Study of preference for surround microphone techniques used in the recording of choir and instrumental ensemble, Archives of Acoustics, 36, 2, $365-378$.

28. SzcZepańska-Antosik J. (2008), Roughness of two simultaneous harmonic complex tones in various pitch registers, Archives of Acoustics, 33, 1, 73-78.

29. Szczerba M., Oomen W., Therssen D. (2011), Parametric audio based decoder and music synthesizer for mobile applications, Archives of Acoustics, 36, 2, 461-478.

30. Witulski B., Łukasik E. (2008), Multimedia presentation of musical instruments, Archives of Acoustics, 33, 1, 35-41.

31. WoŁkowicz J., Kulka Z., KeŠElJ V. (2008), n-gram-based approach to composer recognition, Archives of Acoustics, 33, 1, 43-55.

32. Woszczyk W. (2011), Active Acoustics in Concert Halls - A New Approach, Archives of Acoustics, 36, 2, 379-393.

33. WóJcik J., Kostek B. (2008), Computational complexity of the algorithm creating hypermetric rhythmic hypotheses, Archives of Acoustics, 33, 1, 57-63.

34. ŻWAN P. (2008), Automatic singing quality recognition employing artificial neural networks, Archives of Acoustics, 33, 1, 65-71.

35. JAES - http://www.aes.org/about/

36. MSD photo gallery - http://sound.eti.pg.gda.pl/galeria/gallery.html 